Boletim Científico do Instituto Agronômico do Estado de S. Paulo

Vol. 31

Campinas, julho de 1972

N. ${ }^{\circ} \quad 20$

\title{
NÚMERO MAIS PROVÁVEL E EFICIENCIA DE RHIZO- BIUM AUTÓCTONE PARA SOJA PERENE E SIRATRO EM QUATRO GRANDES GRUPOS DE SOLOS DO ESTADO DE SÃO PAULO $\left.{ }^{(}\right)$
}

Eut Sidney Lopes, engenheiro-agrônomo, Seção de Fertilidade do Solo, L. A. C. Lovadini, engenheiro-agrônomo, Seção de Leguminosas, Hermano GargantinI, engenheiro-agtônomo, Seção de Fertilidade do Solo, e Toshio Igue, engenheiro-agrônomo, Seção de Técnica Experimental e Cálculo, Instituto Agronômico ${ }^{2}$ )

\section{SINOPSE}

Com o objetivo de determinar numericamente a população de Rhizobium que se associa com soja perene e siratro, em quatro grandes grupos de solos do Estado de São Paulo, e avaliar a eficiência dessa população em solo sob cultivo de gramíneas (pastagens) e sob cultivo de soja perene, fo ram conduzidos os ensaios aqui relatados.

Para a determinação numérica de Rhizobium foi utilizada a técnica de "número mais provável". Para a avaliação da eficiência as leguminosas foram cultivadas em vasos de Leonard com solução nutritiva sem nitrogênio e inoculadas com estirpe selecionada e com os solos em estudo.

Os resultados mostraram que o número mais provável de Rhizobium que se associa com soja perene, para os diversos solos sob cultivo de gramíneas, variou de $0,36 \times 10^{2}$ a $15,7 \times 10^{2}$ bactérias/g do solo. Para siratro, esses números variaram de $0,36 \times 10^{2}$ a $126,0 \times 10^{2}$. Para o Latossolo Roxo houve aumento da população que se associa com siratro, por influência do cultivo de soja perene nesse solo.

A eficiência da população autóctone de Rhizobium que se associa com soja perene foi semelhante à de uma estirpe selecionada apenas no caso do solo Podzolizado de Lins e Marília, var. Marília. O cultivo da soja perene não favoreceu significativamente a capacidade de fixação do nitrogênio das estirpes autóctones dos solos estudados.

A eficiência da população autóctone de Rhizobium que se associa com siratro, presente nos solos estudados, foi semelhante à de uma estirpe selecionada, para o caso dos solos Latossolo Vermelho Escuro orto, Latossolo Vermelho Amarelo fase arenosa e Podzolizado de Lins e Marilia, var. Marí-

( $\left.{ }^{1}\right)$ Trabalho apresentado no XIII Congresso Brasileiro de Ciência do Solo, realizado em Vitória, E. S., em 1971. Recebido para publicação em 28 de outubro de 1971.

${ }^{2}$ ) Com bolsas de suplementação do CNPq. 
lia, tendo sido inferior no caso do Latossolo Roxo. O cultivo de soja perene no Latossolo Roxo favoreceu a eficiência da população autóctone.

\section{1 - INTRODUÇÃO}

A soja perene é uma leguminosa que vem sendo recomendada para fins forrageiros desde 1954 (10). Tem uma área plantada estimada em 150.000 ha, no Estado de São Paulo. O siratro, de introdução mais recente, vem despertando grande interesse (9) .

Ambas as leguminosas apresentaram elevado potencial para recuperação de pastagens depauperadas do Estado de São Paulo. Dentre os vários aspectos a serem pesquisados, visando orientação técnica segura na introduçāo de leguminosas em pastagens, a fixação de nitrogênio atmosférico reveste-se de grande importância. Já foi mencionado que toda a leguminosa a ser recomendada como planta forrageira deve, entre outras características, ser uma boa fixadora de nitrogênio atmosférico, pois é disso que depende a economia de nitrogênio pretendida com essa introdução (5) .

Para fixar nitrogênio, a leguminosa deve evidentemente estar nodulada, não sendo, entretanto, a presença de nódulos um indício seguro de que a fixação esteja ocorrendo em níveis satisfatórios. Para que a fixação do nitrogênio ocorra em níveis satisfatórios, a planta e a bactéria dos nódulos devem estar bem supridas dos outros nutrientes, e a nodulação ter sido promovida por estirpes eficientes de Rhizobium. A inoculação das sementes é uma prática normalmente recomendada para assegurar nodulação satisfatória.

Norris e outros (12) verificaram, em ensaio de campo, que a alfafa (Medicago sativa L.) apresenta ampla resposta à inoculação, em solos podzolizados. Os mesmos autores observaram, entretanto, que as leguminosas tropicais, soja perene e amendoim-de-veado, não responderam à inoculação, em Latossolo Roxo e solo Podzolizado, encontrando-se bem noduladas mesmo nos tratamentos não inoculados. $\mathrm{O}$ amendoim também mostrou ausência de resposta à inoculação, em Latossolo Roxo, associada a uma nodulação abundante e aparentemente eficiente, no tratamento sem inoculação (8). Em ensaios com soja perene e siratro, inoculados com solo e estirpes puras de Rhizobium, verificou-se que o cultivo prévio da soja perene favorecia a população autóctone de Rhizobium que nodula siratro, presente no Latossolo Roxo (7). Baseando-se nessas observações e em outras sobre inoculação de soja pe- 
rene (6) sugeriu-se que a população autóctone de Rhizobium de alguns solos do Estado de São Paulo poderia, uma vez supridas as exigências nutricionais da planta, promover nodulação e fixação de $\mathrm{N}_{2}$ satisfatórias, particularmente no caso de siratro, e, possivelmente, no de soja perene.

O presente trabalho foi conduzido com o objetivo de:

a) Avaliar numericamente a população de Rhizobium que se associa com as leguminosas soja perene e siratro, em quatro Grandes Grupos de solos;

b) comparar a eficiência dessa população com a de uma estirpe eficiente;

c) verificar a influência do cultivo de soja perene sobre a eficiência da população de Rhizobium que se associa com soja perene e com siratro.

\section{2 - MATERIAIS E MÉTODOS}

Dois grupos de ensaios foram planejados: um, para avaliar numericamente a população de Rhizobium; outro, para avaliar a eficiência dessa população, em solos sob cultivo de soja-perene e sob vegetação de gramíncas. Todos os ensaios foram conduzidos em casa de vegetação, no Centro Experimental de Campinas, Instituto Agronômico, empregando-se vasos de Leonard com solução nutritiva isenta de nitrogênio e preparados segundo a técnica descrita por Norris (11). Areia de rio, lavada com ácido clorídrico a $5 \%$, foi utilizada como suporte das plantas nos vasos.

Para a avaliação numérica da população, utilizou-se da técnica do "número mais provável" (NMP), descrita por Alexander (1) e adaptada para contagens de Rhizobium em solos, por Clark (2). Em substituição aos recipientes comuns recomendados por Clark (2) utilizaram-se vasos de Leonard, como sugerido por Date e Vincent (3). A solução nutritiva empregada foi a recomendada por Norris (11), para leguminosas tropicais.

O método do NMP, também conhecido por "método da extinção por diluição", avalia numericamente a população de bactérias, sem contá-las individualmente. Consiste em fazer uma série de diluições do material em que se pretende fazer as contagens e inoculá-lo, com repetições, em meio apropriado, onde a presença ou ausência da bactéria seja facilmente detectável. No caso, a formação de nódulos em plantas inoculadas com as diferentes di- 
luições é o indício da presença de Rhizobium. Uma vez constatada a presença ou ausência da bactéria nas diversas diluições e repetições, determina-se o número mais provável de "rizóbios" na amostra, pelo emprego de tabelas apropriadas.

As amostras de solos para todos os ensaios foram retiradas a uma profundidade de $0-20 \mathrm{~cm}$, e compostas de 10 subamostras/ha, para cada local de coleta. As mãos do operador, bem como o trado para retirada de amostras, foram sempre desinfetadas com álcool, antes do início de cada operação. As amostras, acondicionadas em saquinhos plásticos e guardadas em refrigerador até o momento de uso, permaneceram no refrigerador, no máximo, por 13 dias. Por ocasião da inoculação as amostras foram homogenizadas, e as diluições, preparadas a partir de $10 \mathrm{~g}$ de solo. Simultaneamente determinou-se a umidade das amostras. No quadro 1 são apresentados os resultados das análises químicas e um histórico sumarizado das amostras.

As determinações do NMP foram feitas, para os solos LR, LR sob soja, LE, LEa e Pml, com as leguminosas soja-perene e siratro, num total de 10 ensaios.

As inoculações para esses ensaios foram feitas logo após o desbaste, com $1 \mathrm{ml} /$ vaso das suspensões dos solos nas diluições de $10^{-1}, 10^{-2}, 10^{-3}, 10^{-4}, 10^{-5}, 10^{-6}$. Para cada solo foi deixado um vaso sem inoculação, para controle das possíveis contaminações. Esses tratamentos (diluição e controle) foram distribuídos em blocos ao acaso, com três repetições.

Para a comparação da eficiência da população autóctone com a de estirpes puras, e verificação da influência da soja-perene nessa eficiência, foram conduzidos dois ensaios, em blocos ao acaso, com quatro repetições, com tratamentos de a) inoculação com estirpes selecionadas, e b) inoculação com cada um dos solos indicados. Foram mantidos dois tratamentos extras: um, sem adição de nitrogênio e sem inoculação (solução nutritiva sem nitrogênio); outro, com adição de nitrogênio, sem inoculação. Não foram incluídos tratamentos com os solos esterilizados, por ter sido observado, anteriormente, que a quantidade de nitrogênio no inóculo não interfere nos resultados (7). Para o tratamento "Inoculação com estirpe selecionada", utilizou-se a estirpe SMS-137 (=CB-453, CSIRO, Austrália), de alta eficiência em soja perene e siratro. 


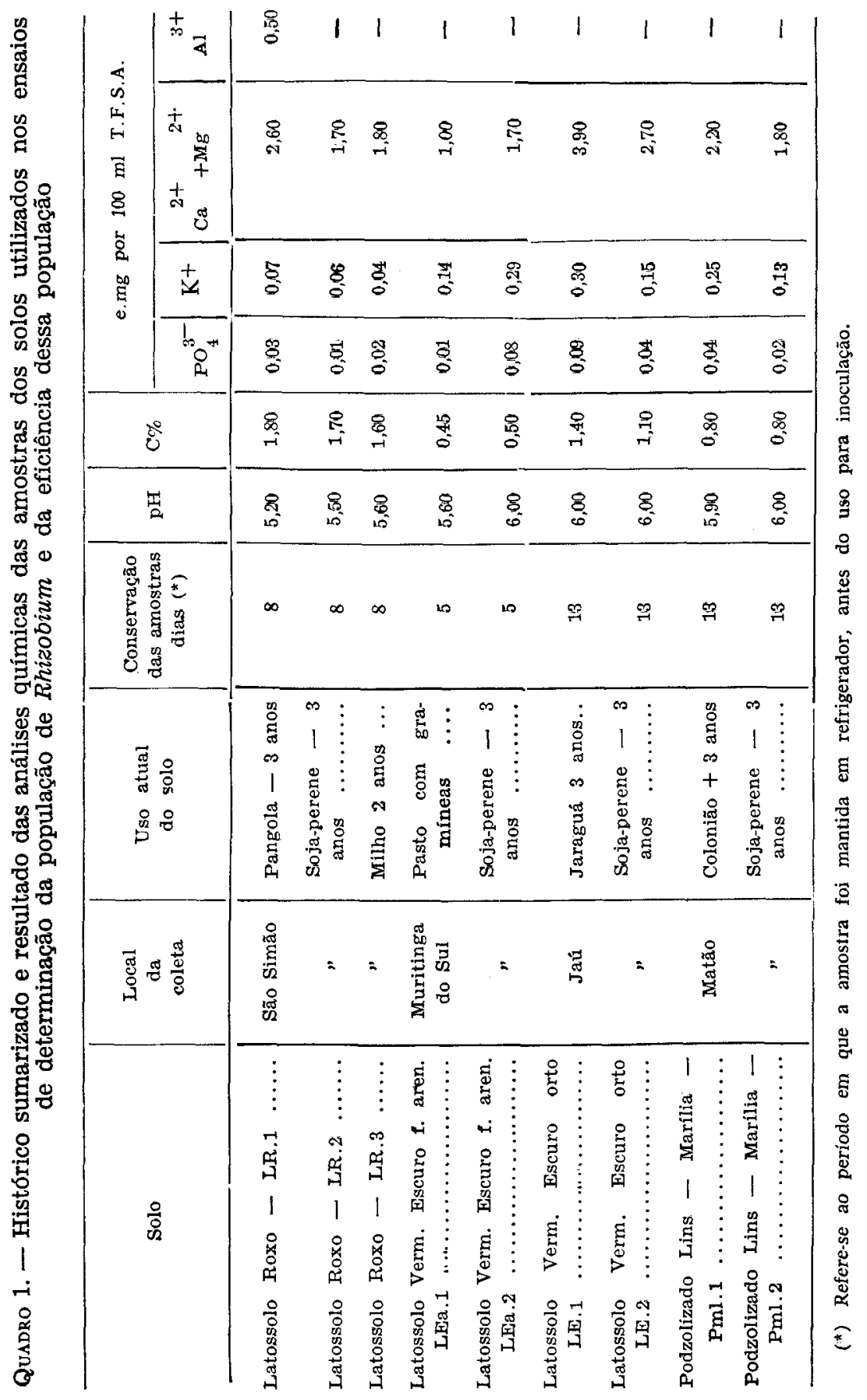


O plantio, no caso dos ensaios de determinação do NMP, e o plantio e as inoculações, nos outros ensaios, foram feitos de modo já descrito (7) . O plantio da soja perene foi feito em 6/10, e o do siratro em $9 / 10 / 70$, para todos os ensaios. O desbaste foi feito aos 6 e 10 dias após o plantio, para soja e siratro, respectivamente. Em ambos os casos foram deixadas duas plantas por vaso. Todas as inoculações foram feitas aos 10 e 13 dias após o plantio, para siratro e soja perene, respectivamente. Mencionados períodos para as adições de nitrogênio nos tratamentos extras foram de 11 e 14 dias. As adições iniciais de nitrogênio foram na base de $10 \mathrm{ml}$ por vaso de uma solução de $\mathrm{NH}_{4} \mathrm{NO}_{3}$ a $1 \%$. Novas adições se fizeram necessárias em 30/11/70, quando as plantas desses tratamentos começavam a amarelecer.

Os ensaios referentes à determinação do NMP foram colhidos em 17/12/70, e os de determinação de eficiência em $19 / 12 / 70$.

\section{3 - RESULTADOS E DISCUSSÃO}

No quadro 2 estão apresentados os resultados de nodulação positiva ou negativa, dos ensaios com os diversos solos, em siratro e soja-perene.

Com base nos resultados obtidos e utilizando a equação de Halverson e Ziegler (4), para cálculo do número mais provável de bactéria, chegou-se ao número de Rhizobium/g de solo, para os diferentes solos estudados. Esses resultados estão apresentados no quadro 3. No quadro 2, pode-se observar que, no tratamento sem inoculação, incluído com a finalidade de verificar a possibilidade de contaminações, elas não apareceram, nos ensaios com sojaperene. Alguns vasos contaminados foram observados nos ensaios com siratro. Fato semelhante observou-se em ensaio anterior (7), tendo-se então indicado que essa leguminosa é mais "promíscua" que a soja perene, e daí a maior facilidade de ocorrerem contaminações. Para o cálculo do NMP não foram considerados os resultados de nodulação positiva, observados em siratro, nas diluições $10^{-3}$ do solo LEa e $10^{-4}$ dos solos LR sob soja e LE sob gramínea.

Comparando os dados de número de Rhizobium/g de solo aqui obtidos com os padrões sugeridos por Vincent (13) observa-se que a população dessa bactéria nos solos estudados é pequena, à 
LOPES \& OUTROS

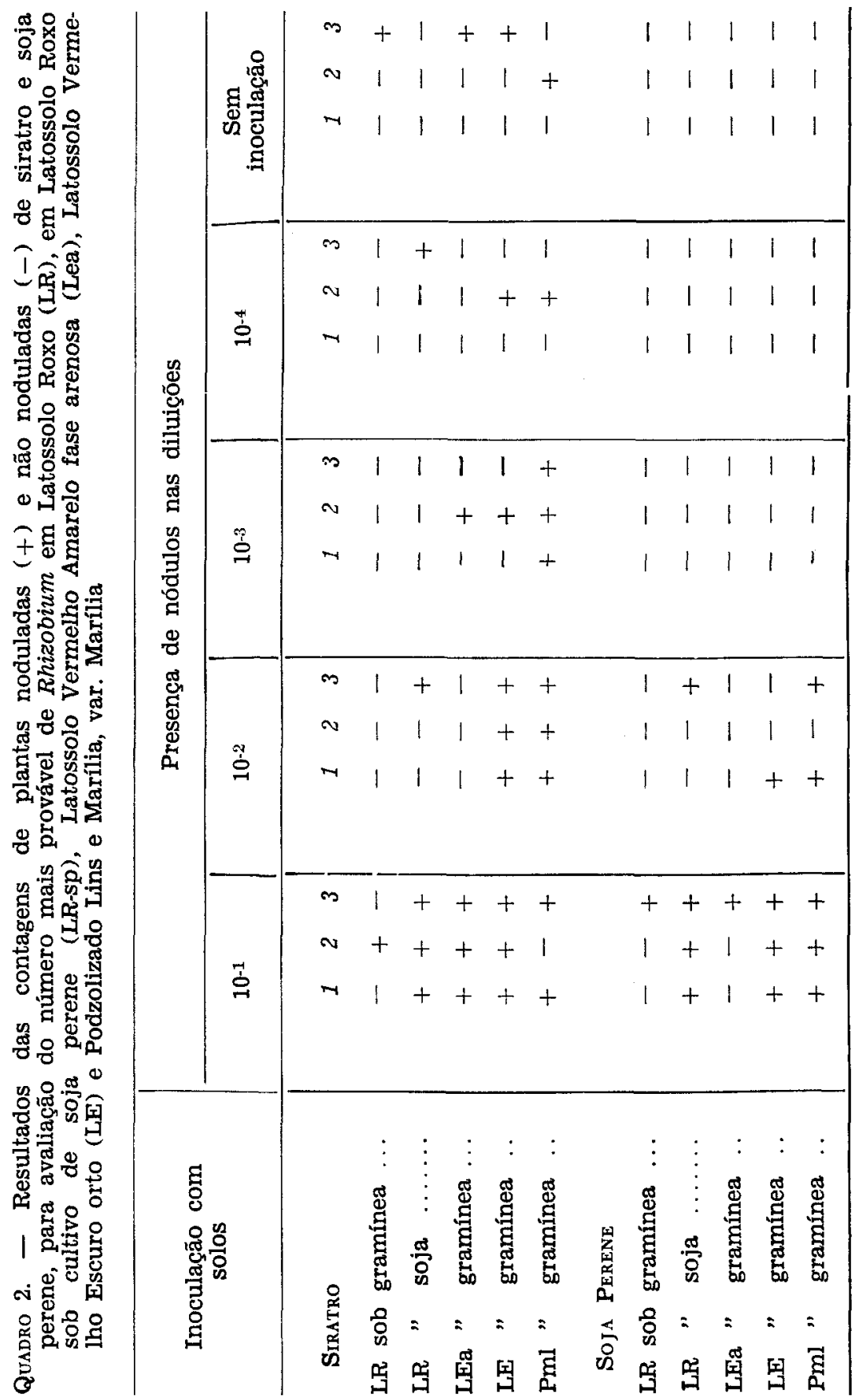


Quadro 3. - População de Rhizobium sp. autóctone de quatro grandes grupos de solos, que se associa com soja perene e siratro. Estimada pela técnica do "número mais provável", com fator 10 diluição e 3 repetições por diluição, em vasos de Leonard

\begin{tabular}{|c|c|c|c|c|c|c|}
\hline \multirow{3}{*}{ Solo } & \multicolumn{3}{|c|}{ Soja-perene } & \multicolumn{3}{|c|}{ Siratro } \\
\hline & \multirow{2}{*}{$\begin{array}{c}R h i z o b i a / g \\
\text { de solo(n.o) } \\
\times 10^{2}\end{array}$} & \multicolumn{2}{|c|}{$\begin{array}{c}\text { Limite de } \\
\text { confiança }\end{array}$} & \multirow{2}{*}{$\begin{array}{c}R h i z o b i a / g \\
\left.\text { de solo(n. }{ }^{\circ}\right) \\
\quad \times 10^{2}\end{array}$} & \multicolumn{2}{|c|}{$\begin{array}{l}\text { Limite de } \\
\text { confianca }\end{array}$} \\
\hline & & inf. & sup. & & inf. & sup. \\
\hline LR sob gramínea .. & 0,36 & 0,07 & 1,68 & 0,36 & 0,07 & 1,68 \\
\hline LR sob soja-perene & 4,24 & 0,90 & 19,70 & 4,24 & 0,90 & 19,70 \\
\hline LEa sob graminea.. & 0,36 & 0,07 & 1,68 & 3,80 & 0,81 & 17,78 \\
\hline LE sob gramínea .. & 4,24 & 0,90 & 19,70 & 15,70 & 3,20 & 7,02 \\
\hline Pm1 sob graminea.. & 9,17 & 1,95 & 42,90 & 126,00 & 26,92 & 589,68 \\
\hline
\end{tabular}

exceção das bactérias do solo Pml que nodula siratro, cuja população poderia ser considerada abundante. Lembrar-se-á que os dados de NMP são uma aproximação pouco precisa, como pode ser observado pelos limites de confiança, a $5 \%$ de probabilidade, apresentados no quadro 3.

As médias de peso seco dos nódulos e das plantas, obtidas nos dois ensaios de avaliação da eficiência de Rhizobium autóctone que nodula soja-perene e siratro, para os solos estudados, estão apresentados no quadro 4. Para a análise estatística não foram considerados os tratamentos sem inoculação, tendo-se tomado como padrão o tratamento de inoculação com a estirpe eficiente, SMS-137, que é esperado como o de maior eficiência. Todos os tratamentos foram comparados com o padrão, usando-se o teste de Dunnet, ao nível de $5 \%$ de probabilidade.

Para peso seco das plantas, no ensaio com siratro o referido teste revelou que apenas os tratamentos de inoculação com Latossolo Roxo sob vegetação de gramínea e sob cultivo de milho foram significativamente inferiores ao padrão. Essa observação vem confirmar resultados anteriores, indicando que esse solo sob cultivo de soja perene favorece uma população autóctone de Rhizobium capaz de nodular siratro. Pela comparação dos dados de peso seco dos tratamentos de inoculação com LR sob soja, e com a estirpe-padrão, nota-se que essa população favorecida é altamente eficiente. Pela observação de $n{ }^{\circ}$ de bactéria nos solos LR e LR 
sob soja (quadro 3), comprova-se que o número de Rhizobium nesses solos aumentou bastante por influência do cutivo de soja perene. E interessante observar que, apesar de ter sido verificada essa influência favorável do cultivo de soja perene em Rhizobium que se associa com siratro, no Latossolo Roxo, esse tipo de influência não se manifestou nos demais solos estudados. Verifica-se pe-

Quadro 4. - Peso seco e nodulação (média) de duas plantas de soja perene e de siratro, observados em vasos de Leonard, em ensaios de inoculação com uma estirpe eficiente de Rhizobium sp e com solos sob diferentes cultivos, de quatro Grandes Grupos

\begin{tabular}{|c|c|c|c|c|c|c|}
\hline \multirow{4}{*}{ Tratamento } & \multicolumn{3}{|c|}{ Soja perene } & \multicolumn{3}{|c|}{ Siratro } \\
\hline & \multicolumn{3}{|c|}{ Peso seco } & \multicolumn{3}{|c|}{ Peso seco } \\
\hline & \multicolumn{2}{|c|}{ Plantas } & Nódulos & \multicolumn{2}{|c|}{ Plantas } & Nódulos \\
\hline & $g / v a s o$ & relativo & $m g$ & g/vaso & relativo & $m g$ \\
\hline Sem inoc., sem $N$ & 0,12 & 4,0 & 0 & 0,20 & 0 & 0 \\
\hline Sem inoc., com $\mathbf{N}$ & 4,00 & 134,0 & 10,0 & 5,30 & 108,0 & 148,0 \\
\hline $\begin{array}{c}\text { Inoc. com estirpe } \\
\text { SMS } 137 \ldots \ldots \ldots\end{array}$ & 2,97 & 100,0 & 164,5 & 4,87 & 100,0 & 146,2 \\
\hline $\begin{array}{l}\text { Inoc. com LR sob } \\
\text { gramínea } \ldots \ldots \ldots\end{array}$ & 0,27 & 9,0 & 12,7 & 2,07 & 42,0 & 133,5 \\
\hline $\begin{array}{c}\text { Inoc. com LR sob } \\
\text { milho } \ldots \ldots \ldots\end{array}$ & 0,67 & 22,0 & 61,7 & 2,67 & 54,0 & 264,2 \\
\hline $\begin{array}{c}\text { Inoc. com LR sob } \\
\text { soja-perene } \ldots\end{array}$ & 1,20 & 40,4 & 80,5 & 4,90 & 100,0 & 231,7 \\
\hline $\begin{array}{c}\text { Inoc. com LEa sob } \\
\text { gramínea } \ldots . . .\end{array}$ & 0,35 & 11,0 & 37,5 & 3,32 & 68,0 & 190,5 \\
\hline $\begin{array}{c}\text { Inoc, com LEa sob } \\
\text { soja-perene } \ldots . .\end{array}$ & 1,65 & 55,5 & 95,2 & 4,92 & 101,0 & 233,2 \\
\hline $\begin{array}{c}\text { Inoc. com LE sob } \\
\text { gramínea } \ldots \ldots\end{array}$ & 1,37 & 46,1 & 84,0 & 4,75 & 97,0 & 263,5 \\
\hline $\begin{array}{c}\text { Inoc. com LE sob } \\
\text { soja-perene } \ldots .\end{array}$ & 1,15 & 38,7 & 85,5 & 4,57 & 94,0 & 199,5 \\
\hline $\begin{array}{c}\text { Inoc. com Pml sob } \\
\text { gramínea } \ldots \ldots \ldots\end{array}$ & 2,47 & 83,1 & 134,5 & 4,20 & 86,0 & 201,0 \\
\hline $\begin{array}{c}\text { Inoc. com Pml sob } \\
\text { soja-perene } \ldots . .\end{array}$ & 0,75 & 25,2 & 40,7 & 4,47 & 92,0 & 272,0 \\
\hline $\mathrm{dms}$ & 1,22 & - & 100,0 & 2,17 & - & n.s \\
\hline $\mathrm{CV}^{\circ} \%$ & 44,0 & - & 58,0 & 25,0 & - & 31,1 \\
\hline
\end{tabular}


lo quadro 3 que a população de Rhizobium autóctone que nodula siratro é numerosa nos demais solos, em comparação com a observada no solo LR sob vegetaçāo de gramínea.

Para os dados de peso seco dos nódulos, observados no ensaio com siratro, não foram constatadas diferenças significativas entre os tratamentos. A variação para esses dados foi bastante grande, tendo sido encontrado um CV da ordem de 58,8\%.

A aplicação do Teste de Dunnet aos dados de peso seco das plantas observadas no ensaio com soja perene revelou que apenas a inoculação com solo Pml foi da mesma magnitude de eficiência observada no tratamento de inoculação com a estirpe selecionada. Em ensaio anterior (7) foram obtidos resultados semelhantes com o solo LR sob vegetação de gramínea e de soja perene, embora naquele ensaio tivesse sido observada forte tendência do cultivo prévio da soja perene influenciar, favoravelmente, a eficiência da população autóctone de Rhizobium.

No quadro 3 verifica-se que o aumento da população de Rhizobium que nodula soja perene no solo LR, por influência do cultivo prévio da soja perene, foi semelhante ao observado com a população da bactéria que nodula siratro. No quadro 4 observa-se que esse aumento da população de Rhizobium nesse solo não correspondeu a um aumento na eficiência dessa população, como verificado para siratro.

Surpreendentemente, a inoculação com solo Pml sob soja perene ocasionou produções inferiores às do mesmo solo sob cultivo de gramínea, sendo este o único tratamento que foi estatisticamente semelhante ao de inoculação com estirpe eficiente. Não se pode, com os presentes dados, adiantar uma explicação para essa observação.

A aplicação do teste de Dunnet aos dados de peso seco de nódulos do ensaio com soja perene indicou que os tratamentos de inoculação com os solos LR sob gramíneas, LR sob milho, LEa sob gramínea e Pml sob soja perene foram, significativamente, inferiores ao tratamento de inoculação com a estirpe selecionada. Isso indica que a nodulação observada por influência da inoculação com aqueles solos foi inferior ao da estirpe eficiente.

Os resultados das análises químicas dos solos, apresentados no quadro 1 , mostram que as características químicas dos diversos 
solos sob as vegetações indicadas e sob cultivo de soja perene não diferiram a ponto de interferir na interpretação dos resultados.

$\mathrm{O}$ cultivo prévio de milho não teve nenhuma influência na população da bactéria que nodula soja perene ou siratro, presentes no Latossolo Roxo (quadro 4).

Embora os dois ensaios não tenham sido planejados para fins comparativos, e nem a adição de nitrogênio tenha sido incluída com o mesmo fim, algumas observações podem ser feitas por comparação dos resultados, nos dois ensaios. Considere-se que esses ensaios foram conduzidos num mesmo compartimento de estufa, instalados na mesma época, e os tratamentos efetuados da mesma forma, no mesmo dia. Pela observação dos índices de produção, apresentados no quadro 4 , tomando-se como valor 100 a produção obtida no tratamento de inoculação com a estirpe eficiente, em siratro nota-se que a produção nesse tratamento foi bastante próxima àquela observada no tratamento com adição de nitrogênio. Por outro lado, com exceção dos solos que se mostraram significativamente inferiores ao padrão (LR e LR sob milho), as produções também foram comparáveis àquelas obtidas no tratamento com adição de nitrogênio. Já no ensaio com soja perene os resultados são bem diferentes. O tratamento de adição de nitrogênio foi em $34,0 \%$ superior ao melhor tratamento de inoculação, com estirpe selecionada. Com exceção do solo Pml, que não diferiu significativamente da inoculação com estirpe seleciona$\mathrm{da}$, os demais tratamentos produziram no máximo 55,5\% (solo LEa sob soja) da produção do tratamento-padrāo. Esses resultados indicam que a capacidade de fixação de nitrogênio de siratro deve ser maior que a de soja perene.

Evidentemente os resultados aqui obtidos não são conclusivos, com relação à necessidade de inoculação dessas leguminosas, em condições de campo. Eles sugerem, entretanto, que possivelmente siratro não responde à inoculação nos solos Latossolo Vermelho Escuro orto, Latossolo Vermelho Escuro fase arenosa e Podzolizado de Lins e Marília, pois a população de Rhizobium autóctone que se associa com essa leguminosa é altamente eficiente. $\mathrm{O}$ fato de essa população ser pequena nos dois primeiros solos mencionados não seria limitante, pois os "rizóbios" presentes se multiplicariam na rizosfera da planta e promoveriam nodulação satisfató- 
ria. Com relação à soja perene os dados indicam maior possibilidade de resposta à inoculação.

\section{4 - CONCLUSÕES}

Os resutados obtidos permitem as seguintes conclusões:

a) O número mais provável de Rhizobium presente no Latossolo roxo, e que nodula soja perene e siratro, está próximo de 36,0 bactérias/g de solo. Para o mesmo solo, sob cultivo de soja perene, essa população é de $4,24 \times 10^{2}$ bactérias/g do solo, notando-se portanto que o cultivo da soja perene faz aumentar o população de Rhizobium capaz de promover nodulação em siratro e soja perene. Para os solos Latossolo Vermelho Escuro orto, Latossolo Vermelho Escuro fase arenosa e Podzolizado de Lins e Marília, essa população foi de $15,7: \times 10^{2}, 3,80 \times 10^{2}$ e $126,0 \times 10^{2}$, para siratro, e de $4,20 \times 10^{2}, 0,36 \times 10^{2}$ e $9,17 \times 10^{2}$, para soja perene, respectivamente.

b) A nodulação e a capacidade de fixação de nitrogênio das estirpes autóctones observadas $\mathrm{em}$ siratro, em virtude da inoculação com os solos LE, LEa e Pml, foi da mesma magnitude que a observada por inoculação com estirpes selecionadas. Para esses solos não houve influência do cultivo da soja perene na eficiência de fixação das estirpes autóctones. A fixação de nitrogênio por bactérias presentes em Latossolo Roxo foi inferior àquela observada pela inoculação com estirpe selecionada. Para esse mesmo solo houve influência favorável do cultivo da soja perene, sendo que a fixação de nitrogênio observada por inoculação do solo LR sob cultivo de soja atingiu a mesma magnitude que a inoculação com estirpe selecionada.

c) A capacidade de fixação do nitrogênio e a nodulação $\mathrm{em}$ soja perene observada no tratamento de inoculação com solo Pml foram semelhantes à observada no tratamento de inoculação com estirpe selecionada. Por outro lado, a fixação do nitrogênio causada pela inoculação com os solos LR, LE e LRa foi inferior à observada no tratamento de inoculação com estirpes selecionadas, embora a nodulação no solo LE tenha sido da mesma magnitude que a provocada por aquele tratamento. O cultivo de soja não favoreceu a eficiência da população autóctone capaz de nodular soja perene a ponto de a fixação ser comparável à eficiência de uma estirpe selecionada. 
MOST PROBABLE NUMBER AND EFFICIENCY OF PERENNIAL SOYBEAN AND SIRATRO RHIZOBIA INDIGENOUS TO FOUR SOIL GREAT GROUPS OF SAO PAULO STATE

\section{SUMMARY}

Experiments were carried out in glass-house, in order to evaluate the number and efficiency of native rhizobia nodulating perennial soybean and siratro in four soils under grasses and perennial soybean vegetations.

All the experiments were carried out in Leonard jars; the efficiency of native rhizobia was compared with the effective SMS-137 (=CB453) strain.

Results have shown that the MPN of Rhizobium nodulating perennial soybean in soils under grasses were between $0.36 \times 10^{2}$ and $15.7 \times 10^{2}$. For siratro, higher populations were observed and the numbers were between $0.36 \times 10^{2}$ and $126.0 \times 10^{2}$. It was also observed that the population of Rhizobium nodulating siratro and perennial soybean, in the Latosolic $B$ Terra Roxa under vegetation of perennial soybean is higher than under pangola grass (Digitaria decumbens Stent), or corn.

The efficiency of indigenous Rhizobium which associates with perennial soybean was similar to that of the strain SMS-137 for the Podzolized Soil on Calcareous Sandstone-Marilia variation, but not for the others soils (Dark Red Latosol Sand Phase, Ortho Red-Yellow Latosol, and Latosolic B Terra Roxa). Previous cropping with perennial soybean did not affected significantly the efficiency of perennial soybean rhizobia.

The efficiency of indigenous rhizobia which associates with siratro was lower than that of strain SMS-137 only in the case of the Latosolic B Terra Roxa. Previous cropping with perennial soybean has increased the efficiency of siratro Rhizobium, indigenous to that soil.

\section{LITERATURA CITADA}

1. ALEXANDDER, $M$. Most probable number method for microbial populations. In: BLACK, C. A., ed. Methods of soil analysis Chemical and microbiological properties. Madison, American Society of Agronomy, 1965 . v.2, p.1467-1472.

2. CLARK, F. E. Rhizobia. In: BLACK, C. A., ed. Methods of soil analysis - Chemical and microbiological properties. Madison, American Society of Agronomy, 1965. v.2, p.1487-1492.

3. DATE, R. A. \& VINCENT, J. A. Determination of the number of root-nodule bacteria in the presence of other organisms. Aust. J. exp. Agric. Anim. Husb. 2:5-7, 1962.

4. HALVORSON, H. O. \& ZIEGLER, N. R. Aplication of statistics to problems in bacteriology: I - A mean of determining bacterial populations by the dilution method. J. Bacteriol. 25:101-121, 1933.

5. LOPES, E. S. Considerações gerais sobre leguminosas forrageiras. Trabalho apresentado no I Encontro de Técnicos da Região Centro-Sul para Discussão de Problemas Relacionados às Leguminosas Forrageiras. Nova Odessa, 1969, 9fls. (Mimeografado)

6. - LOVADINI, L. A. C.; GARGANTINI, H. \& MIYASAKA, S. Efeito comparativo de diversos materiais para revestimento, em "peletização", na nodulação e fixação do nitrogênio em soja perene (Glycine wightii Verdc). Bragantia 31:XIII-XVIII, 1972. (Nota 4). 
7. LOPES, E. S.; LOVADINI, L. A. C., GARGANTINI, H., MIAYSAKA, S. \& LEON, J. C. Capacidade fixadora de nitrogênio de Rhizobium autóctone associado com soja perene e siratro, em dois solos do Estado de São Paulo. Bragantia 30:145-154, 1971.

8. —; TELLA, R.; ROCHA, J. L. V. \& IGUE, T. Inoculação de sementes de amendoim (Arachis hypogaea L.). Bragantia 31:XXVII-XXXIV, 1972. Nota 6.

9. LOVADINI, L. A. C. Algumas informações sobre siratro. O Agronômico 20:41, 1968.

10. Cultura da soja perene. Campinas, Instituto Agronômico, 1968. 28p. (Boletim 186)

11. NORRIS, D. O. Techniques used in work with Rhizobium. In: Some concepts and methods in sub-tropical pasture research. Farnham Royal, Commonw. Agric. Bur., 1964. Bull. 47. p.186-198.

12. — LOPES, E. S. \& WEBER, D. F. Incorporação de matéria orgânica e aplicação de péletes de calcário com estirpes de Rhizobium em experimentos de campo sob condições tropicais. Pesq. agropec. brasil. 1971. (No prelo)

13. VINCENT, J. M. A manual for the practical study of the root nodule bacteria. London, Beackwell Scientific Publications, 1970. 159p. (IBP Handbook, 15) 